\section{Compendium ARQ: Casas de Temporada}

Obras de Andrade y Morettin (Brasil), Barclay \& Crousse (Perú),

Rafael Iglesia (Argentina),

Mathias Klotz,

Mauricio Léniz,

Cecilia Puga y Cazú Zegers, entre otros.
Siguiendo en la línea del Compendium ARQ: Generación del 90, esta publicación se plantea como una recopilación de obras realizadas en el último tiempo alineadas bajo un tema común, que en este caso es dado por el encargo y el programa: la segunda vivienda, o como hemos titulado esta revisión, la "casa de temporada". Un tipo de casa que se caracteriza por dar lugar a los tiempos de distensión y de ocio, en lugares alejados del cotidiano urbano y que generalmente se sitúan con cierta holgura en los terrenos en que se encuentran.

Es particularmente interesante darse cuenta que este tipo de encargo resulta ser de alguna forma una liberación: algunas veces para el cliente, quien ve aquí una oportunidad para plasmar todas sus aspiraciones estéticas, su imaginario espacial, o sus ideas de cómo se debe vivir una casa; en otros casos, como en la mayoría de las obras aquí presentadas, es el arquitecto quien se toma estas licencias y utiliza el proyecto de la casa como ejercicio arquitectónico.

18 fueron las obras seleccionadas, emplazadas en lugares variados y distantes entre sí: Farellones, en la cordillera de Los Andes; la vegetación extrema de los alrededores de Sao
Paulo; el desierto de la costa peruana, o la selva fría del Lago Villarrica.

Dentro de este conjunto de casas aparecen operas primas de arquitectos que recién inician su carrera y obras de arquitectos consagrados; algunas de ellas podrían transformarse, por su propuesta respecto al programa, el tratamiento de la materialidad o por la radicalidad del proceso proyectual, en nuevos referentes en lo que respecta a la arquitectura de la vivienda en Chile.

Con esta publicación intentamos consolidar un nuevo espacio como editorial: siguiendo en el espíritu de la revista ARQ 51, en este Compendium incluimos tres obras de arquitectos sudamericanos: una peruana, una argentina y una brasileña. Más allá de las diferencias o similitudes entre la manera de enfrentar la arquitectura que pudieran existir entre los diferentes países, y sin pretender abanderar ni agrupar arquitectos "latinoamericanos", tratamos de abrir otro canal de difusión que permita el intercambio dentro de Sudamérica y la difusión del trabajo de nuestros arquitectos en el mundo.
Editado por Ediciones ARQ Facultad de Arquitectura, Diseño y Estudios Urbanos
Pontificia Universidad Católica de Chile

Serie Compendium ARQ

Vol. 2

$22 \times 27 \mathrm{~cm}$

80 pásinas, color

Texto en castellano e inglés

En librerías desde

marzo de 2003
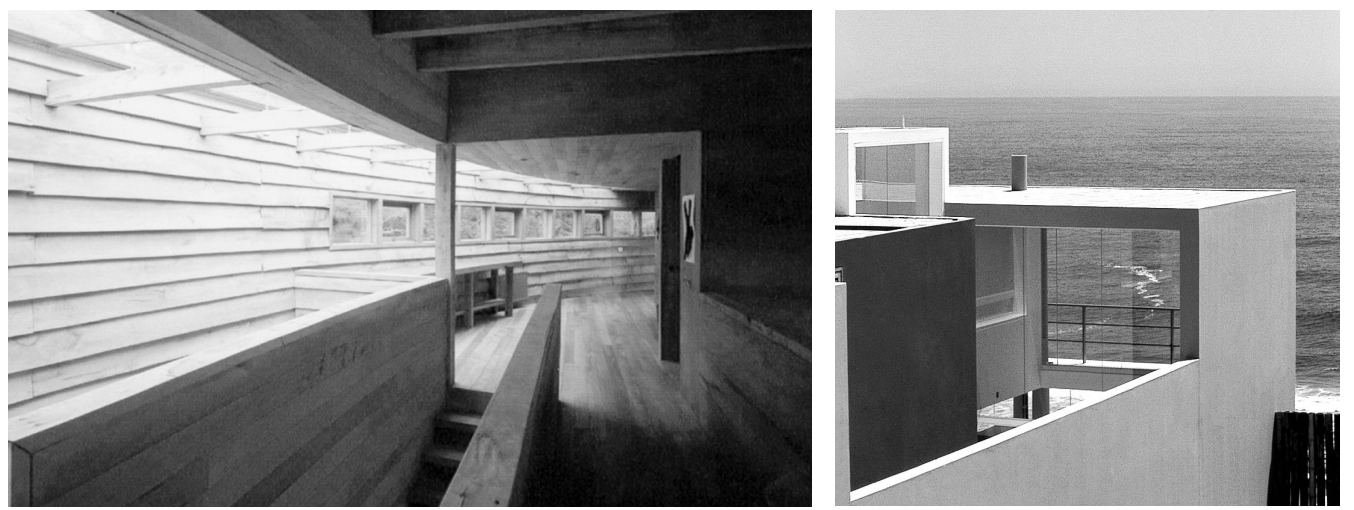
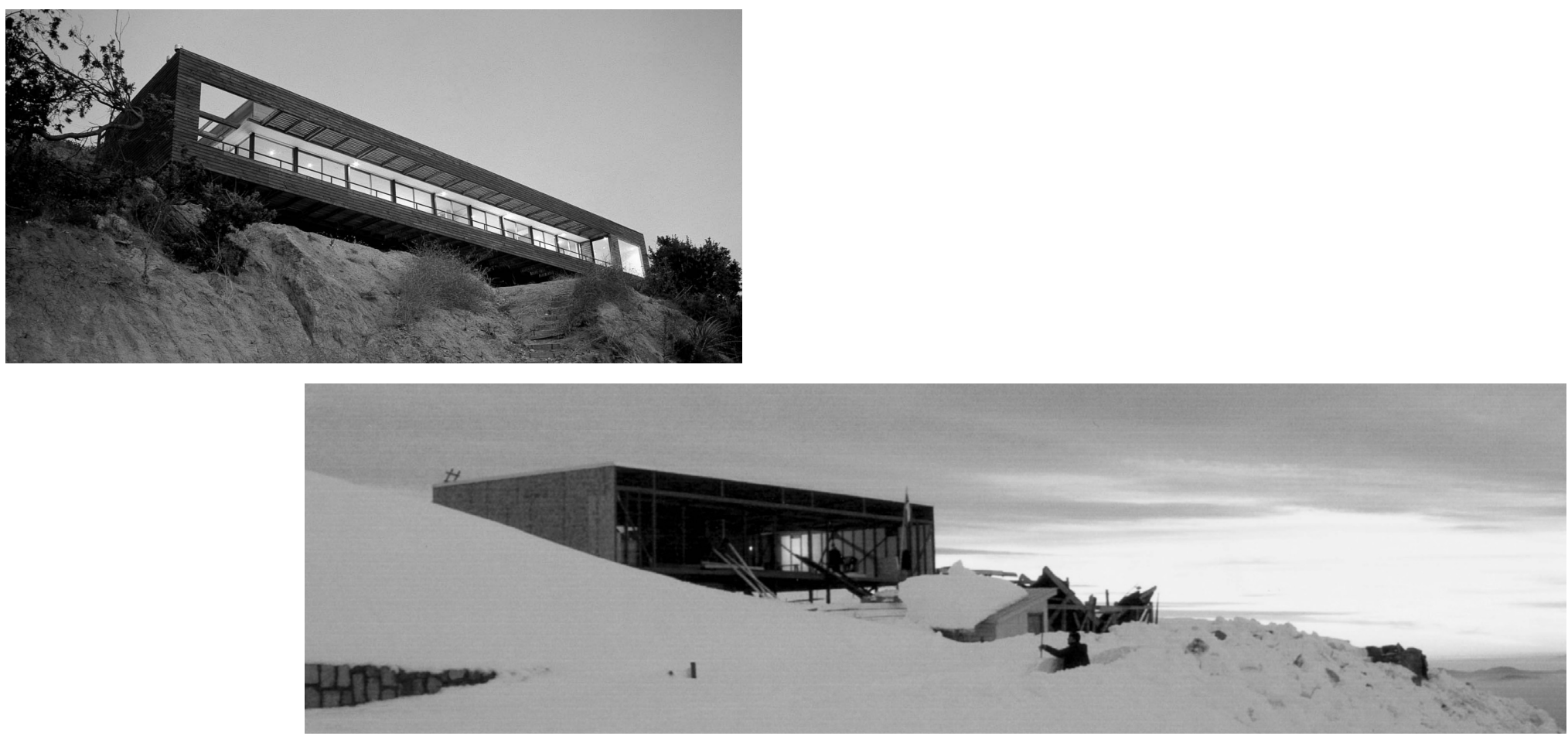